\title{
Las alegorías de la Fe en el arte occidental
}

\author{
Allegories of Faith in Western Art
}

Luís Mariano Akerman

\section{Resumo}

As alegorias funcionam como pilares de significado na civilização ocidental. Na Idade Média, as alegorias da Fé emergem nas artes visuais como figuras retóricas, cuja origem encontra-se em modelos do mundo clássico. Desde a Baixa Idade Média em diante, as alegorias da Fé foram gradualmente transformadas. Nos tempos modernos, um fator decisivo foi o efeito devastador da Segunda Guerra Mundial, ao que a Igreja Católica respondeu em 1965, com a declaração Nostra Aetate. Em torno a este documento ocorrem mudanças, incluindo a elaboração de alegorias da Fé mais consoantes aos nossos tempos. A disputa dá espaço ao diálogo. Contudo, um atributo ambíguo pode ainda ser detectado em várias alegorias da Fé - a venda, cuja estranha presença cobrindo os seus olhos é simbólica e manifestase como um paradoxo visual.

Palavras-chave: Representação alegórica. Catolicismo. Judaísmo. Diálogo interreligioso.

\section{Sinopsis}

Las alegorías funcionan como pilares de significado en la civilización occidental. En la Edad Media, las alegorías de la Fe emergieron en las artes visuales como imágenes retóricas, su origen remontándose a figuras del mundo clásico. A partir del medioevo tardío, tales alegorías fueron gradualmente transformadas. En los tiempos modernos, un factor decisivo fue el efecto 
devastador de la Segunda Guerra Mundial, al que la Iglesia católica respondió en 1965 con la declaración Nostra Aetate. En torno a este documento se producen cambios, incluyendo la elaboración de alegorías de la Fe más consonantes con nuestro tiempo. El desencuentro cede terreno al diálogo. Con todo, un atributo de doble filo puede aún ser detectado en varias alegorías de la $\mathrm{Fe}$ - la venda, cuya extraña presencia cubriendo los ojos de las mismas es simbólica y se manifiesta como una paradoja visual.

Palabras clave: Representación alegórica. Catolicismo. Judaísmo. Diálogo interreligioso.

\section{Abstract}

Allegories function as bearers of meaning in Western civilization. In medieval times, allegories of Faith emerged in the visual arts as rhetorical figures, their sources of inspiration relating to classical models. From the late Middle Ages onwards, such allegories were gradually transformed. In modern times, one decisive factor occurred in the aftermath of the Second World War, when in 1965 the Catholic Church responded with Nostra Aetate. Around this declaration changes take place, including the elaboration of allegories of Faith which are more consonant with our times. Conflict gives place to dialogue. However, an equivocal attribute can still be detected in various allegories of Faith - the blindfold, whose strange presence is symbolic and can be understood as a visual paradox.

Keywords: Allegorical representation. Catholicism. Judaism. Interfaith dialogue.

\section{Introducción}

Si como afirma Saint-Exupéry, "lo esencial es invisible", ¿cómo es ello expresado en las alegorías de la Fe propias de las artes visuales? Para responder a este interrogante es necesario explorar el tema desde sus raíces. Con tal propósito, el presente trabajo: (1) Delimita la naturaleza y

${ }^{1}$ SAINT-EXUPÉRY, Antoine de. Le Petit Prince (1943). París: Gallimard, 1951, cap. XXI. 
especificidades de la alegoría en el campo de las artes visuales. (2) Explica los conceptos que propulsaron el gradual desarrollo de las alegorías de la Fe en el arte occidental. (3) Analiza las transformaciones de las alegorías de la Fe a lo largo de la historia, considerando tanto las pasadas como aquellas de nuestro tiempo. (4) Reconsidera la venda como atributo, explorando su significado fundamental, con base en la relación entre lo visible y aquello que no lo es.

\section{Alegoría y artes visuales}

El término alegoría proviene del griego allegorein, "expresar figuradamente". ${ }^{2}$ En el campo de las artes visuales, la alegoría aspira proveerle una imagen a una idea abstracta o noción moral que no la posee, posibilitando que dicho concepto - frecuentemente difícil de ser aprehendido — sea esbozado o ilustrado y pueda entonces ser comprendido. En este sentido específico, la alegoría da forma tangible a una abstracción, es decir, hace visible aquello que es sólo conceptual. Representación de lo invisible, ${ }^{3}$ la alegoría nace con el fin de ejemplificar y suele abrigar una intención didáctica. ${ }^{4}$

En la historia del arte, se entiende por alegoría a la figura humana que transmite un concepto abstracto. Las alegorías son a menudo figuras femeninas provistas de atributos que contribuyen a identificarlas. Así, por ejemplo, la alegoría de la Justicia es una mujer con balanza en mano y sus ojos vendados, en tanto que la alegoría de la Muerte es un esqueleto provisto de un reloj de arena y una guadaña. ${ }^{5}$ La mayoría de las alegorías conocidas posee sus orígenes en el mundo clásico. ${ }^{6}$ Ellas fueron cultivadas

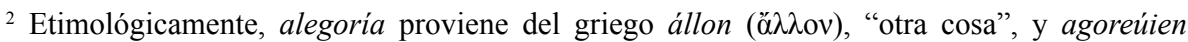

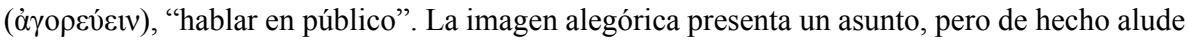
a otro, ya sea el último una idea, concepto, valor o institución.

${ }^{3}$ BLANC, J. "L'allégorie: l'invisible et sa représentation". In: Histoire visuelle de l'art. París: Larousse, 2001, pp. 212-13.

${ }^{4}$ El significado usual del término alegoría equivale a un "dicho de otro modo" o bien un "puesto en otras palabras". Debido a ello, la alegoría puede relacionarse con el arte de ejemplificar con elocuencia.

${ }^{5}$ Para ilustraciones de ambas alegorías y numerosas otras que se consideran en el presente estudio, véase AKERMAN, Luís Mariano. "Las alegorías de la Fe". Asterisk, 21 de diciembre de 2015, <http://akermariano.blogspot.com/2015/12/fe.html>.

${ }^{6}$ Los orígenes visuales de la alegoría se remontan a la escultura helenística (c. 200-190), cuando los artistas, inspirados por la Oportunidad de Lisipo, se interesaron por temas introspectivos y desarrollaron entonces alegorías escultóricas para ser "leídas"; HONOUR, H.; FLEMING, J. 
a lo largo de la historia del arte, en especial durante los períodos medieval, renacentista, manierista, barroco, romántico y simbolista. ${ }^{7}$ Cesare Ripa se ocupa de las alegorías en su tratado iconográfico, Iconología (1593), que en su segunda edición de 1603 las ilustra mediante 150 grabados, intentando servir a poetas y artistas a representar en términos alegóricos las virtudes y los vicios, los sentimientos y las pasiones: con tal propósito provee entonces las descripciones, atributos y colores simbólicos de las alegorías, a menudo a partir del legado clásico. ${ }^{8}$

Más allá del posible realismo o grado de apariencia real con que sean representadas, las alegorías no son seres reales, sino figuras imaginarias: personificaciones que trabajarían a modo de ejemplo, mas pertenecen todas al dominio de la ficción. En el arte, donde dominante fue durante siglos la

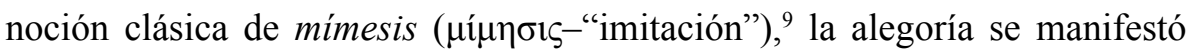
como un tipo particular de representación, expresándose como transposición consciente y representación indirecta. ${ }^{10}$ Debido a que responde a un lenguaje velado, ${ }^{11}$ la alegoría tiende a involucrar un doble significado: uno superficial o literal, que va siempre acompañado por otro, secundario, pero más profundo que el primero. ${ }^{12}$ Con todo, la alegoría llega a veces a poseer múltiples niveles de significado. ${ }^{13}$

A World History of Art. Londres, 1991, pp. 154-155. Las alegorías fueron también cultivadas en el arte romano. Considérense el relieve de Tellus Mater (Madre Tierra; Ara Pacis Augustae, Roma); la personificación del Oikoumene (Totalidad de la Tierra Habitada) coronando a Augusto en la Gemma Augustea (KHM Museum, Viena); y los cuatro efebos del Sarcófago de las Estaciones, c. 220-230 (Metropolitan Museum, Nueva York).

${ }^{7}$ Ejemplos: Virtudes y Vicios (Giotto, 1304-1313), Primavera (Botticelli, c. 1478), las Cuatro Estaciones (Arcimboldo, 1563-1573), Triunfo de la Muerte (Leal, 1672), Libertad lidera al pueblo (Delacroix, 1830), Esperanza (G.F. Watts, 1886).

${ }^{8}$ RIPA, Cesare. Iconologia overo descrittione dell'imagini universali, 2a ed., Roma: Lepido Facij, 1603.

${ }^{9}$ OLIVERAS, Elena. Estética: la cuestión del arte. Buenos Aires: Ariel, 2006, pp. 72-88.

10 “Alegoría. Ficción que presenta un objeto al espíritu, de modo que despierte el pensamiento de otro objeto" (GARCÍA-PELAYO, R. Pequeño Larousse Ilustrado. París: Larousse, 1977, p. 46). La alegoría es también transposición consciente del plano conceptual al artístico (BECKER, U. The Continuum Encyclopedia of Symbols. Londres: Continuum, 1994, p. 13).

${ }^{11}$ LIDDELL, H.G.; SCOTT, R. A Greek-English Lexicon. Oxford: Clarendon Press, 1940: "Allegory".

${ }^{12}$ LUCIE-SMITH, Edward. Art \& Civilization. Londres: Lawrence King, 1992, p. 546.

${ }^{13}$ Como estructura artística, la alegoría genera dobles o múltiples significados. FLETCHER, A. "Allegories in Literary History". In: WIENER, P. Dictionary of the History of Ideas. Nueva York: Charles Scribner's Sons, 1973-1974, vol. I, p. 41. 
Por ser figuras de la retórica, las alegorías no son ajenas a la dialéctica ni a la didáctica. Imágenes visuales que ilustran un concepto abstracto, valor o institución, las alegorías sirven a veces como recursos educativos, pero también son susceptibles de ser empleadas con fines ideológicos, propagandísticos y/o proselitistas. ${ }^{14}$

\section{Pistis, Fides y Fe}

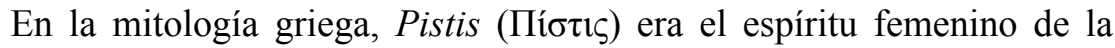
Confianza y la Lealtad. ${ }^{15}$ Aunque diosa menor, ella pertenecía a un grupo de personificaciones tales como Elpis (Esperanza), Sofrosina (Prudencia) y Carites (las Gracias). Dichas divinidades eran asociadas a la honestidad y la armonía en el ámbito social. Según el mito clásico, Pistis era un espíritu bueno, pero se escapó de la caja de Pandora y huyó al Olimpo, abandonando así la humanidad. ${ }^{16}$ En otro ámbito, y acaso inesperadamente, el Judaísmo helenístico de la Septuaginta recurrió precisamente a la palabra griega pistis para traducir el término hebreo emunah (אמונה) y expresar así cuestiones relativas a la $\mathrm{Fe}^{17}$

Pistis, por otra parte, fue introducida como Fides en la cultura romana, donde figura como diosa y como concepto personificado en textos de Ovidio, Estacio y otros autores latinos. ${ }^{18}$ Numa Pompilio promovió el culto a Fides en Roma, creándose su templo en la Colina Capitolina, exactamente en el lugar donde el Senado romano preservaba los acuerdos y tratados estatales con países extranjeros. Tales documentos eran todos protegidos por Fides. En esa gran ciudad, Fides era además invocada mediante una gran variedad de denominaciones,

\footnotetext{
${ }^{14}$ ROWE, Nina. "Idealization and Subjection at the South Façade of Strasbourg Cathedral". In: MERBACK, M., ed. Beyond the Yellow Badge: Anti-Judaism and Antisemitism in Medieval and Early Modern Culture. Leiden: Brill, 2007, pp. 179-202.

${ }^{15}$ En un artículo de 1916, Eduard Fraenkel consideró que fides (versión latina de pistis) no sólo concierne la esfera de la creencia sino también aquellas de la transacción comercial, el derecho y la política. MORGAN, Teresa. Roman Faith and Christian Faith: Pistis and Fides in the Early Roman Empire and Early Churches, Oxford UP, 2015, p. 5. Las figuras antitéticas de Pistis eran Apate (Decepción) y Pseudologoi (Mentiras). ATSMA, A.J. "Pistis". In: Theoi, Nueva Zelanda, 2015.

${ }^{16}$ Teognis de Megara, Fragmentos elegíacos (548-45), 1.1135.

${ }^{17}$ MORGAN, Faith, pp. 8-10.

${ }_{18}$ OVIDIO, Metamorfosis, 5.43ff; ESTACIO, Tebaida, 11.98ff; PLUTARCO, Numa, 16; APIANO, Bella Civilia, 1.16; DIO CASSIUS, Historia romana, 45.17.
} 
preferentemente como Fides publica (populi romani) y Fides militum. ${ }^{19}$ Apelando respectivamente a la confianza cívica y a la lealtad militar, esas expresiones tomaron la forma de inscripciones en monedas romanas del período imperial (sestercios, denarios y antoninianos, siglos II-III), donde figuran acompañando a Fides, personificada en ellas como la alegoría de la Confianza y la Lealtad. En su papel de Fides publica, la figura lleva un recipiente con frutas y un manojo de trigo, ambos simbólicos de los alimentos destinados al pueblo. Como Fides militum, la diosa porta un cetro de mando e insignias militares, tales como el estandarte de la legión romana o la bandera de una de sus secciones, conocida en latín como vexillium. ${ }^{20}$

Con el tiempo, Fides fue eventualmente asociada con la esfera de la retórica y la demostración de una verdad. ${ }^{21}$ Debido a ello, como técnica retórico-persuasiva, pistis creó un puente entre la retórica clásica y la teología cristiana. ${ }^{22}$ En retórica, los griegos entendían por pistis al discurso persuasivo elíptico que se concentraba más sobre "emoción y efecto" que sobre "la representación de la verdad". ${ }^{23}$ El Cristianismo, no obstante, puso el énfasis en lo segundo, ligando la idea de pistis a cuestiones relativas a la Fe. Una relación estrecha entre pistis y persuasión fue así desarrollada a lo largo de discusiones cristianas en torno a la Fe. ${ }^{24}$ Entendida como técnica retórica, pistis era empleada para persuadir mediante la lógica, llegando a funcionar como evidencia durante la demostración de la veracidad de cierto argumento. ${ }^{25}$ En este contexto, sin embargo, es menester recordar que Aristóteles mismo oportunamente presentó reservas acerca de la efectividad de pistis y, en su Retórica, él

\footnotetext{
${ }^{19}$ ROLDÁN, José Manuel, et al. Historia de Roma. Ediciones Cátedra, 1999, tomo II: “E1 Imperio Romano".

${ }^{20}$ WELCH, B. "Fides: Loyalty and Trust", The Sign Language of Roman Coins, 18 de octubre de 2008.

${ }^{21}$ GRIMALDI, William. "A Note on Pisteis in Aristotle's Rhetoric, American Journal of Philology, 78:2 (1957), pp. 188-192.

${ }^{22}$ MORGAN, Roman Faith and Christian Faith, passim.

${ }^{23}$ CHERRY, R. A Rhetoric of Doing Essays on Written Discourse: Pistis, Expression and Belief, S. Illinois UP, 1992, p. 134.

${ }^{24}$ TONSTAD, Sigve K. Saving God's Reputation: The Theological Function of Pistis Iesou in the Cosmic Narratives of Revelation. Londres: T\&T Clark, 2006.

${ }^{25}$ ABIZADEH, Arash. The Passions of the Wise: Phronesis, Rhetoric, and Aristotle's Passionate, Practical Deliberation. Philosophy Education Society, 2002.
} 
hasta llega a contradecirse cuando la considera alternativamente lógica e ilógica. ${ }^{26}$

\section{Las alegorías de la Fe a través del tiempo}

\subsection{Manifestaciones y desarrollos del pasado}

En Europa, el arte cristiano medieval recurrió frecuentemente a un par de alegorías teológicas al que se conoce en latín como Ecclesia et Synagoga. ${ }^{27}$ Elaboradas a partir de las alegorías de Fides militum y Fides publica como modelos de inspiración, pero concebidas a su vez en los términos de una dicotomía maniqueísta, Ecclesia et Synagoga solían aludir a disputas teológicas entre la Fe católica y la Fe mosaica. ${ }^{28}$ Recurrentes en el discurso eclesiástico medieval, tales alegorías fueron incorporadas en los campos de la prédica, la literatura y el drama, así como también en las artes visuales. En el arte cristiano, que en por entonces comunicaba "la voz de Dios a la comunidad católica", ${ }^{29}$ las alegorías de Ecclesia et Synagoga constituían recursos teológicos que procuraban ejemplificar abstracciones. ${ }^{30}$ En términos visuales, el par alegórico en cuestión fue plasmado principalmente en escultura y pintura. ${ }^{31}$

A partir del siglo IX, las figuras de Ecclesia y Synagoga figuran junto a la Crucifixión en relieves de marfil carolingios y otonianos. Allí, cada alegoría de la Fe representa además a su respectiva congregación de creyentes. Provista de un estandarte cruciforme, Ecclesia colecta en un cáliz la sangre que emana

\footnotetext{
${ }^{26}$ Retórica, 1354-1356; GRIMALDI, “A Note on Pisteis in Aristotle's Rhetoric”, p. 188, n. 3. ${ }^{27}$ ROSS, Leslie. Medieval Art, Greenwood Publishing Group. 1996, pp. 73-74.

${ }^{28}$ La principal fuente literaria de inspiración para la ejecución de las alegorías de la Fe es $D e$ Altercatio Ecclesiae et Synagogae, texto del siglo V equivocadamente atribuido a Agustín de Hipona (354-430). Allí, ambas alegorías dialogan.

${ }^{29}$ MICHAEL, Robert. A History of Catholic Antisemitism. Palgrave-Macmillan, 2008, pp. $39-46$.

${ }^{30}$ REUTER, Jasmín. "Alegoría de la Sinagoga". Revista de la Universidad de México 20:1 (1965), pp. 18-20.

${ }^{31}$ Las representaciones de Ecclesia et Synagoga son numerosas. Comprenden estatuas, vitrales, relieves, manuscritos miniados, objetos litúrgicos, tallas, murales, tapices, mosaicos y pinturas. Más de setenta representaciones del par en cuestión han sobrevivido hasta hoy. Algunas de ellas fueron y continúan siendo restauradas. Existen registros históricos de ellas y no pocas réplicas. SCHILLER, Gertrud. Ikonographie der christlischen Kunst, 5 vols., Gütersloh, 1976, 4, pt. 1: 45-68, 242-245.
} 
del cuerpo de Cristo. Synagoga suele observar a Jesús en la cruz, aunque en algunos casos mira en otra dirección o se aleja, evitando así ver lo que sucede en el Gólgota. ${ }^{32}$

En el siglo XII, el par alegórico tiende a expresar la así-llamada "teoría de la substitución", que sostiene que un nuevo pacto es establecido tras la muerte de Jesús en la cruz - uno a través del cual Ecclesia reemplaza a Synagoga. Es decir, la alianza entre Dios e Israel pierde su validez y el Judaísmo su liderazgo en materia espiritual, siendo éste último conferido a Ecclesia, con quien a partir de entonces Dios establece "la nueva alianza" y le otorga exclusivamente a Ecclesia la autoridad sobre el magisterio espiritual. ${ }^{33}$ En el arte europeo medieval, Synagoga representa el Judaísmo, mas interpretado como la "antigua" alianza con Israel, mientras que Ecclesia simboliza el Cristianismo, entendido como el nuevo pacto, que queda establecido al morir Jesús en la cruz. ${ }^{34}$ Concebidas para transmitir la tesis doctrinaria que proclama el triunfo teológico del Cristianismo sobre el Judaísmo, ${ }^{35}$ y basadas a su vez sobre la rígida doctrina eclesiástica medieval que predicaba recurriendo a contraposiciones maniqueístas, Ecclesia et Synagoga fueron representadas en las artes visuales como un par dialéctico tan antinómico como problemático. ${ }^{36}$

Ambas figuras femeninas son generalmente bellas y elegantes, pero la actitud corporal y atributos de cada una comunican ideas opuestas. Así, Ecclesia aparece erguida y segura de sí misma. Ella porta un estandarte cruciforme, el cáliz eucarístico con la sangre del Cristo y una corona bien implantada sobre su cabeza. Diferente es la condición de Synagoga, cuya actitud corporal, abatida y cabizbaja, transmite pérdida y frustración. ${ }^{37}$

\footnotetext{
${ }^{32}$ BISHOP, Nancy. "An Iconographical Study of the Appearance of Synagoga in Carolingian Ivories”. In: UTTERBACH, K. T.; PRICE, M. L., eds., Jews in Medieval Christendom: "Slay Them Not". Leiden: Brill, 2013, pp. 7-24.

${ }^{33}$ VLACH, Michael J. Has the Church replaced Israel?. Nashville: B\&H Publishing Group, 2010.

${ }^{34}$ REUTER, “Alegoría de la Sinagoga”, pp. 18-19.

${ }^{35}$ ROSENAU, Helen. "Ecclesia et Synagoga”. Encyclopedia Judaica, 2008.

36 RAPHAËL, Freddy. "L'Église et la Synagogue: l'évolution du thème”. ASIJA: Alsacia-Lorena, 2010.

${ }^{37}$ Ello es reminiscente del pathos de "Iudaea Capta", la cautiva y melancólica alegoría de Sión, visible en monedas imperiales romanas acunadas por Vespasiano para conmemorar la conquista de Judea y la destrucción del Templo de Jerusalén en el año 70. Dichas monedas fueron a su vez reemitidas por sus hijos, Tito y Domiciano, durante veinticinco años. LIMOR, Ora. Jews and Christians in Western Europe (Евреи и христиане). Ra'anana: Open University, 2012, pt. 1, fig. 5.
} 
Remitida a sí misma, Synagoga se presenta cohibida. ${ }^{38}$ Sus atributos son una lanza o estandarte quebrado, las tablas de la Ley mosaica (a las que difícilmente sostiene e incluso son representadas en posición invertida), así como una corona a punto de caérsele de la cabeza, a veces ya caída, o bien inexistente. Prominente, misteriosa e inquietante en el imaginario alegórico tradicional es la venda que cubre persistentemente los ojos de Synagoga. ${ }^{39} \mathrm{Y}$, mientras Ecclesia proclama aquello que el Catolicismo medieval percibía como su propio triunfo teológico, Synagoga expresa aquello que los católicos percibían como la trágica condición del Judaísmo, derrotado, quebrado o en ruinas, ${ }^{40}$ debido a limitaciones supuestamente inherentes a dicho credo y que en el arte son simbolizadas a través de la venda que cubre los ojos de Synagoga. ${ }^{41}$

Ecclesia et Synagoga transmiten un mensaje de desencuentro y antagonismo. En Estrasburgo, por ejemplo, él es expresado en contrastantes términos de victoria y derrota: Ecclesia dirige "una mirada altiva y arrogante" a Synagoga. ${ }^{42}$ En términos visuales, tal antagonismo se volvió antijudío desde el momento en que se intentó proclamar la presunta superioridad del Cristianismo, ${ }^{43}$ acompañada de una especie de fosilización del Judaísmo, ${ }^{44}$ alegorizándoselo al último como errado, anacrónico e incluso

\footnotetext{
${ }^{38}$ No obstante, la figura de Synagoga en el arte cristiano es la manifestación de una abstracción y no un reflejo de la real dinámica religiosa, económica y cultural judía en Europa medieval. ROWE, "Idealization and Subjection", pp. 190-202.

${ }^{39}$ FAÜ, Jean-François. L'image des Juifs dans l'art chrétien médiéval. París: Maisonneuve \& Larose, 2005, figs. 11, 15, 17-18, 22-24. COMAY, Joan. The Diaspora Story, Tel Aviv: Steimatzky, 1981, pp. 138-139. KNIESMEYER, Joke; BRECHER, D.C. "The Middle Ages". In: Beyond the Pale, Holanda, 1995. RODRÍGUEZ BARRAL, Paulino. La imagen del judio en la España medieval, Barcelona, 2008, figs. 2, 5-14. LIMOR, Jews and Christians, pt. 1, figs. 4, 7, 9-11, 13, 15, 16, 37.

${ }^{40} \mathrm{VLACH}$, Has the Church replaced Israel?, pp. 51-52.

${ }^{41}$ Para la teología cristiana medieval, Synagoga representaba la religión judía personificada, con sus ojos cubiertos ante el Cristo, en tanto que Ecclesia encarnaba la religión católica, entendida como la única verdad posible. REUTER, p. 19.

42 Ibid. "Alegoría de la Sinagoga", p. 20.

${ }^{43}$ Exégesis medieval de 2 Corintios 3.

${ }^{44}$ FREUD, Sigmund. Der Mann Moses und die monotheistische Religion: Drei Abhandlungen, Ámsterdam: De Lange, 1939. Sostiene que el Cristianismo al Judaísmo lo fosilizó: con el Cristianismo, la religión judía pasó a ser "una especie de fósil".
} 
amoral. ${ }^{45}$ En este contexto, poco a poco surgió un contraste alegórico extremo entre la determinación de Ecclesia y la inhibición de Synagoga, representada como vulnerable, resignada y dócil. ${ }^{46}$ En el arte ideológico medieval, el antagonismo teológico se volvió palpable a partir de los siglos XII y XIII. Ecclesia pareció entonces desear la extinción y el ulterior reemplazo de su supuesta rival, Synagoga, quien desde entonces fue alegoría del Judaísmo, pero entendido como un credo vetusto, obsoleto y trascendido. ${ }^{47}$ Ante la Synagoga "derrotada", el arte ideológico del medioevo proclamó a Ecclesia como la única vencedora. ${ }^{48}$ Alegoría del Catolicismo, Ecclesia fue representada entonces como la Iglesia "triunfante". 49 Con todo, el par alegórico de Ecclesia et Synagoga constituye un importante testimonio sobre el discurso teológico clerical que prevaleció en Europa durante casi dos mil años. ${ }^{50} \mathrm{Y}$, si bien la Iglesia católica canonizó la santidad de numerosos hebreos bíblicos, ella a su vez también tomó distancia del pueblo de Israel y sus descendientes no convertidos al Cristianismo, tolerándolos en ciertos casos, mas estigmatizándolos en otros. ${ }^{51}$ En el arte eclesiástico, la venda que cubre los ojos de Synagoga se supone que indica tanto su "ceguera espiritual" ante "el verbo hecho carne" como su propia incapacidad de percibir la "luz que emana del Evangelio". 52

\footnotetext{
${ }^{45}$ Considérese, por ejemplo, Berthold Furtmeyr, Misal de Salzburgo, Ratisbona, 1478-1489: imagen con "El árbol de la muerte y la madera de la vida", donde Eva alimenta con la manzana del pecado a los hebreos (custodiados por la Muerte) y es representada como antítesis de la Virgen María, quien da la hostia a los cristianos (protegidos por un ángel); Múnich, Bayerische Staatsbiliothek, Ms. Clm 15708-721, vol. III, fol. 60v. Desnuda y habiendo ya engañado a Adán, Eva alude al legado mosaico, en tanto que coronada y provista de aureola, María representa al Evangelio (especialmente 2 Corintios 3).

${ }^{46}$ MAIER, Hans. Die Binde vor den Augen?"e. Stimmen der Zeit 11 (2013), pp. 723-733.

${ }^{47}$ ROWE, "Idealization and Subjection", pp. 179-202.

${ }^{48}$ Tal como emerge de la inicial "Q" representando el "El triunfo de Ecclesia sobre Synagoga" en las Homilias de Beda, Verdún, siglo XII: triunfante, Ecclesia figura allí con sus conocidos atributos y de pie, parada sobre el inerte cuerpo de una Synagoga horizontal y yaciente, unívocamente derrotada e identificable sólo por la venda que cubre sus ojos.

${ }^{49}$ MICHAEL, Catholic Antisemitism, pp. 40-42.

${ }^{50}$ KIRSCHBAUM, Saul. “Adversus Iudaeos”. Devarim 20 (2013), pp. 45-50.

${ }^{51}$ FAÜ, J.-F. L'image des Juifs dans l'art chrétien médiéval, passim. LIMOR, Jews and Christians, passim. En el ápice del medioevo, los israelitas constituían una minoría segregada en Europa.

${ }^{52}$ Juan, 1, 14; 9, 35-37. SCHILLER, Ikonographie der Christlischen Kunst, vol. 4, pt. 1, pp. 45-56, 242-245. REUTER, “Alegoría”, p. 19. RESNIK, Judith; CURTIS, D. Representing Justice, New Haven: Yale UP, 2011, p. 65: "Synagoga blind to the Light of Christianity". Ibid. "From Fool's Blindfold to the Veil of Ignorance", Yale Law Report, 58:1 (2011), pp. 14-16.
} 
Espinoso y cuestionable, el mensaje ideológico medieval es proyectado sobre imágenes que pretenden representar al Judaísmo, pero de hecho sólo lo segregan y estereotipan..$^{53}$ Así, una venda cubre los ojos de la apesadumbrada Synagoga esculpida para la catedral de Estrasburgo en el siglo XIII, ${ }^{54}$ mientras que en la anónima Fuente de la Gracia (óleo, c. 1430-1455), otra venda más cubre los ojos del Sumo Sacerdote de Israel, presente allí como alegoría masculina del Judaísmo y debido a ello también representado él en términos de inestabilidad, con los rollos de la Ley cayéndosele por el suelo. ${ }^{55}$ Mas el símbolo no debe en este caso confundirse con la alegoría, dado que la alegoría es el concepto vuelto persona (Judaísmo personificado a través del Sumo Sacerdote), en tanto que actitud corporal, vestiduras e indumentaria, junto con el inquietante atributo "caído" (la Ley mosaica por el suelo) son todos ellos símbolos, representados para caracterizar e identificar a la mencionada alegoría, de modo que ella pueda ser "leída" e interpretada. Con todo, José Eduardo Cirlot expresa en su Diccionario de símbolos tradicionales (1958) que prácticamente todas las alegorías han sido elaboradas a consciencia y por ello difícilmente sean algo más que "creaciones artificiales". ${ }^{56}$ En tal sentido, Synagoga sería una presunción teológica del antiguo clero y fiel reflejo de un persistente antijudaísmo. ${ }^{57} \mathrm{O}$ sea, el Judaísmo no tal como era, sino como en ese entonces se procuraba que fuese.

\footnotetext{
${ }^{53}$ VLACH, Has the Church replaced Israel?, pp. 51-52.

${ }^{54}$ REUTER, “Alegoría de la Sinagoga”, pp. 18-20.

${ }^{55}$ Museo Nacional de Prado, Madrid. Óleo estilísticamente refinado e interreligiosamente tóxico. NIREMBERG, David. "The Judaism of Christian Art". In: Judaism and Christian Art, University of Pennsylvania, 2011, pp. 387-427. Desde el siglo XI y hasta fin del siglo XIX, la imaginería de Ecclesia et Synagoga fue a menudo empleada en Europa con propósitos antijudíos. En la catedral de Notre Dame en París, los ojos de Synagoga son cubiertos por una serpiente, símbolo del pecado: enroscada en su cabeza, ella simboliza el presunto origen de la "ceguera". Varias miniaturas del Breviari d'Amor (1288) presentan demonios como autores de la "ceguera" judaica. La Bible historiée de Haguenau (siglo XV) incorpora a Ecclesia recogiendo la sangre del Cristo en un cáliz, mientras que Synagoga es violentamente enceguecida por un demonio negro. Montada sobre un burro y con una venda cubriendo sus ojos, Synagoga es por último literalmente apuñalada por la Lebende Kreuz (Cruz viviente), surreal y extravagante creación teológica adoptada en Italia, Austria y Alemania (siglos XV y XVI).

${ }^{56}$ CIRLOT, José Eduardo. A Dictionary of Symbols. Londres: Routledge, 1971, pp. xli-xlii: "Symbol and Allegory".

${ }^{57}$ GREGERMAN, Adam L. "Memorializing the New Relationship between Jews and Catholics", 50 Years of a Journey of Friendship, Saint Joseph's University, 25 de septiembre de 2015.
} 
Como respuesta a la imaginería ideológica de Synagoga, una figura alegórica fue representada en un libro de plegarias hebreo-alemán del medioevo. ${ }^{58}$ El manuscrito miniado en cuestión presenta una reina sentada en un trono y portando una corona. La figura lleva sus ojos cubiertos por una venda, recordando aquella que identifica a Synagoga en el arte católico, ${ }^{59}$ pero siendo a su vez también evocativa de la tradición hebrea que evita todo contacto visual con el entorno físico cuando la bendición sobre las velas del Shabat o al recitar el Shemá Israel ${ }^{60}$ En el manuscrito, la reina es acompañada por un joven con sombrero judío. ${ }^{61}$ Él toma la mano de la soberana y le declara fidelidad. La escena fue incorporada dentro del Cantar de los Cantares. En ella se destaca la palabra hebrea "CONMIGO" (את), ${ }^{62}$ así como otros motivos concurrentes o entrelazados, reforzando todos ellos la idea de unión. La soberana es la amada de Israel. Como conjunto, la escena sugiere la incondicional devoción del creyente judío para con su Fe mosaica, que es alegorizada aquí a través de la figura de la reina entronizada y coronada. ${ }^{63}$ Los ojos vendados de la misma evocan en términos visuales el compromiso expresado por los hebreos en Éxodo 24,7: "haremos y oiremos" (נעשה ונשמע). ${ }^{64}$

Tras la Revolución Francesa, Synagoga es representada en un grabado que muestra a Napoleón reestableciendo la libertad de culto de los israelitas en 1806. Allí la alegoría del Judaísmo es identificable por medio de atributos tales como las tablas de la Ley, el candelabro de los siete brazos y el arca de la Alianza. La figura alegórica se encuentra sentada sobre el piso y requiere la asistencia del emperador. Sin embargo, la venda ha desaparecido aquí por

\footnotetext{
${ }^{58}$ Mahzor Levi, Hamburgo, c. 1350. Hamburgo, Staats- und Universitätsbibliothek, Levi 37 , fol. $169 v$.

${ }^{59}$ BARTHAL, Ruth. "Medieval Images of 'Sacred Love': Jewish and Christian Perceptions". Assaph 2 (1996), pp. 93-110.

${ }^{60} 2$ Corintios 4, 18 es compatible con la tradición hebrea en cuestión.

${ }^{61}$ Judenhut. Sombrero amarillo del medioevo, obligatorio en Europa para los judíos a partir de disposiciones del Concilio de Letrán IV (1215). Segregaba al israelita residente entre cristianos como "judío de señal". Condujo a la discriminación.

62 "Conmigo del Líbano, oh novia mía. Conmigo ven del Líbano" (Cantar de los Cantares 4, 8; Torá).

${ }^{63}$ Tal como sucede con la Torá, ella ocupa una posición de privilegio y porta además una corona que le es propia.

${ }^{64}$ Es decir, ante todo se hará lo que Dios indique y sólo luego se oirá aquello que motiva Su voluntad (Torá).
} 
completo, dando lugar a una expresiva mirada por parte de Synagoga. Esta última pone de manifiesto que Synagoga no era necesariamente "ciega", sino que la venda que hasta entonces portaba, le había transitoriamente impedido la visión.

El trono y la corona de la alegoría de la Fe mosaica reaparecen en una ilustración realizada por el artista gráfico judío Ephraim Moses Lilien para Judá, un libro de poesías inspiradas en la Biblia y escritas por su amigo cristiano Börries von Münchhausen (Berlín, 1900-1). Representada en estilo modernista y cubierta por un manto ornado con caracteres hebreos, la alegoría de la Fe mosaica porta en su regazo la Torá. Por tratarse de una figura femenina, este aspecto particular constituye una innovación de vanguardia dentro de la sociedad patriarcal de la época. La alegoría de Lilien es a su vez "Judea, hija de Sem", Novia de la Presencia Divina (שכינה-Shejiná), la "Reina del Shabat". ${ }^{65}$ Joven y confidente en sí misma, ella posee una mirada expresiva, simultáneamente profunda y serena.

Inesperadamente, en la misma época en que Lilien representó una alegoría de la Fe mosaica con los ojos abiertos, Mariano Beillure esculpió una venda sobre aquellos de su Alegoría de la Fe católica en la catedral de Cuenca. Hecha de mármol blanco, la imagen porta en sus manos un cáliz del cual asoma una hostia consagrada, alusiva al misterio de la Eucaristía. La figura carece en este caso de la tradicional cruz latina. Señalemos aquí que a lo largo de la historia, el Cristianismo desarrolló tres tipos de alegorías de la Fe: Ecclesia, la Santa Fe y la Fe católica. Todas ellas son provistas de cáliz eucarístico y cruz latina. Ecclesia lleva una corona sobre su cabeza. En la fachada principal de la catedral de Notre Dame en París, Ecclesia presenta además una aureola, simbolizando su santidad y aludiendo a su vez a la noción de la Santa Fe católica. Con excepción de la corona, los atributos mencionados reaparecen todos en la alegoría de la Santa Fe, que es representada con aureola o bien sin ella. Este último aspecto establece una sutil relación entre la alegoría de la Santa Fe y aquella de la Fe católica. En su Iconología (1603), Ripa describe e ilustra la Alegoría de la Fe católica, otorgándole los Testamentos de las Escrituras Sagradas, una vela y un corazón por atributos. ${ }^{66}$ Mas los artistas raramente llevaron a la práctica tan

${ }^{65}$ Las nociones de Novia del Shabat y Reina del Shabat tienen su origen en el Zohar, siglos II-XIII; son retomadas en el hasta hoy vigente "Himno Laudatorio del Shabat" de rabí Isaac Luria, siglo XVI: allí, ella brilla como en los tiempos bíblicos.

${ }^{66}$ RIPA, Iconologia, 1603, p. 151: "Fede Cattolica". 
copiosas premisas y prefirieron remitirse al cáliz y la cruz. ${ }^{67}$ Siendo venerada en Lucena, exhibida en importante trono y portando cáliz brillante y pesada cruz, la alegoría de la Fe católica (1843) año tras año "sigue"-con sus ojos vendados - al Cristo de la Pasión durante las procesiones de la Semana Santa en España. ${ }^{68}$

Debido a que, tradicionalmente, nada necesita la Fe corroborar a través del sentido de la vista, las alegorías católicas de la Fe fueron representadas enceguecidas, con sus ojos cerrados, o bien cubiertos por un velo semitransparente. ${ }^{69}$ Es en España donde particularmente frecuentes son las imágenes de la Santa Fe y la Alegoría de la Fe católica, presentadas ambas con una venda que cubre sus ojos. En El triunfo de la España católica sobre la herejía, pintura ejecutada por Felipe de Silva en 1712, el rey Felipe V es acompañado por una alegoría de la Fe católica que porta cáliz y hostia, en tanto que una venda impide su visión. ${ }^{70}$ Otra notable alegoría de la Fe es "España defensora de la Fe católica" (Fernando Cruz Solís, 1944-1965), figura que lidera uno de los grupos escultóricos del Monumento al Sagrado Corazón de Jesús sobre el Cerro de los Ángeles, en Getafe. ${ }^{71}$ A diferencia de la anterior, esta alegoría no lleva cáliz, mas abraza una robusta cruz latina. Tal como ocurre con su predecesora, también ella lleva una venda que le cubre los ojos, para sugerir así la noción de Fe ciega.

Sólo en España existen no menos de quince alegorías de la Fe católica con su visión impedida por la venda. Un importante referente visual europeo para ellas se encuentra en un Palmesel de madera del siglo XV preservado en la iglesia de San Quirino, en Luxemburgo. ${ }^{72}$ Se trata de una imagen exhibida y reverenciada durante el Domingo de Ramos. En el Palmesel se observan tres jóvenes montadas todas sobre un mismo borrico. Alegóricamente,

${ }^{67}$ LÓPEZ BURGOS, M. "La representación de la Santa Fe en el arte”, Revista Fe y Hermandad, Lucena, 2013, pp. 48-57.

${ }^{68}$ COFRADÍA DE LA SANTA FE. Revista Fe y Hermandad, 2013, pp. 1, 3-4, 15, 38-39, 44-45.

${ }^{69}$ Fides (Giotto, 1313; Cappella dell'Arena, Padua); Fe (Rafael, 1507; Altar Baglioni, Pinacoteca Vaticana); $\mathrm{Fe}$ (Moretto da Brescia, 1545; Hermitage, San Petersburgo), El triunfo de la $\mathrm{Fe}$ (Juan Frías y Escalante, 1677; Prado); Alegoría de la Fe (Tiépolo, 1755; Santa María de la Piedad, Venecia) y Alegoría de la Fe católica (Goya, 1781; Basílica del Pilar, Zaragoza).

${ }^{70}$ Obra preservada en el Palacio Real de Aranjuez. LLULL, Josué. "Felipe V matando la herejía ante El Escorial", Arte e Iconografia, 14 de julio de 2011, <http://www.arteiconografia. com/2011/07/felipe-v-matando-la-herejia-ante-el.html>.

${ }^{71}$ FARFÁN, Lourdes M. "Getafe: El Cerro de los Ángeles”, Una ventana desde Madrid, 11 de diciembre de 2013.

${ }^{72}$ López Burgos. "Santa Fe en el arte”, pp. 48-49. 
ellas representan las tres Virtudes Teologales - Caridad, Fe y Esperanza. Prominente en tal composición es el atributo que identifica a Fe: una gruesa venda que cubre sus ojos. En el arte católico, todas las alegorías de la Fe con venda sobre sus ojos evocan en términos visuales lo expresado en Hebreos 11, 1: "La fe es la certeza de aquello que esperamos y la prueba de las cosas que no vemos".

Entre el medioevo y la modernidad, la relación entre la alegoría de la Fe católica y aquella de la Fe mosaica raramente fue fácil. Aunque inicialmente concebidas como un par dialéctico, las disputas y el prejuicio contribuyeron a su desencuentro y aislamiento. En un dieciochesco relieve marmóreo de la iglesia de San Moisés en Venecia, Synagoga y Ecclesia fueron esculpidas compartiendo una misma escena, pero son separadas por una serie de motivos simbólicos. Tales motivos incluyen nubes de las que emergen haces de luz y, apoyado sobre el suelo, un globo terráqueo. Junto al último pueden verse un águila, un toro y un león, animales simbólicos todos ellos y con referentes en la Biblia. En el firmamento, sobre las nubes y los haces de luz, ha sido representada una paloma. Las alegorías de la Fe fueron ambas esculpidas como personificaciones sedentes, con sus atributos respectivos y distribuidas a ambos lados del mencionado grupo de símbolos. Synagoga sobre el lado derecho del relieve; Ecclesia sobre el lado izquierdo del mismo. Ecclesia lleva la mitra papal, el cáliz eucarístico y la cruz latina. La alegoría de la Fe mosaica porta las vestiduras y accesorios propios del Sumo Sacerdote de Israel, incluyéndose entre ellos el cuadrado pectoral con las doce gemas que simbolizan a las tribus israelitas. ${ }^{73}$ Encontrándose aquí librada de la venda que por siglos había cubierto sus ojos en el arte católico y provista ahora de un puntero y las tablas de la Ley mosaica con los estatutos de la Alianza grabados en caracteres hebreos, Synagoga se dispone a enseñar el importante patrimonio preservado por Israel. Sólo que en ese preciso momento, Ecclesia mira en la dirección opuesta, ignorándola. En efecto, en términos de actitud corporal, la parte inferior del cuerpo de Ecclesia se encuentra aún posicionada en dirección a Synagoga, dando a entender que ambas pudieron hasta ese momento haber estado entablando un diálogo. Pero, en el relieve, el tronco de Ecclesia crea a su vez una figura serpenteada: la posición del rostro, al ser considerada en relación a aquella de las piernas, habla de una rotación de $180^{\circ}$. Y pese a tan drástico movimiento, la alegoría

${ }^{73}$ Éxodo 28, 15-21. 
de la Fe católica puede verse portando el cáliz y la cruz sin mayor dificultad. Mas eso no es todo, ya que el puntero que Synagoga sostiene en su mano parece haber amenazado a la paloma, representada en vuelo en el relieve. Así, al descender del firmamento, el ave - análoga en simbolismo a una Mano de Dios - vuela en dirección a Ecclesia. Significativamente, aunque las vendas de las alegorías de la Fe sean aquí inexistentes, las dificultades en materia de diálogo no llegan a superarse.

\subsection{Manifestaciones y desarrollos de nuestro tiempo}

Finalizada la Segunda Guerra Mundial y conociéndose ya la magnitud de ese factor histórico decisivo que fue "la atrocidad sin precedentes de la Shoá" (el asesinato de dos tercios de las comunidades judías europeas en manos de los nazis y sus colaboradores) ${ }^{74}$ las autoridades de la Iglesia católica, reunidas en el Concilio Vaticano II, elaboraron un documento fundamental para la reanudación de las relaciones entre el Catolicismo y el Judaísmo. Aprobada en octubre de 1965 por amplia mayoría de votos, la declaración Nostra Aetate promueve desde entonces el diálogo entre ambos credos y toma como punto de partida el respeto mutuo y la cooperación interreligiosa. ${ }^{75}$

Con el tiempo, la influencia de las premisas conciliatorias enunciadas en Nostra Aetate se hace sentir en el dominio de las artes visuales. En 1999, como reacción al Holocausto, Franz Hämmerle realiza una talla para la capilla de Dachau, Synagoga et Ecclesia: Madre e Hija, obra donde alegóricamente Synagoga es protegida por Ecclesia, quien la acompaña, abraza y contiene en un gesto solidario. Ambas figuras fueron representadas de pie y a las dos se las ve frágiles y delgadas. Ecclesia lleva su cabeza cubierta, mientras que aquella de Synagoga se encuentra expuesta, luego de haber sido rapada. Para sugerir la idea de filiación, ambas figuras fueron talladas a partir de un mismo tronco. En 2007, por otra parte, Bert Menko elabora Synagoga et Ecclesia, un grabado donde las dos alegorías ocupan el centro del trabajo. ${ }^{76}$ Synagoga porta un pequeño candelabro de siete brazos con sus luminarias encendidas. Respecto

\footnotetext{
${ }^{74} \mathrm{KoCH}, \mathrm{K}$. "Theological Questions and Perspectives in Jewish-Catholic Dialogue," Conferencia ICCJ, Nueva Jersey, 2011.

${ }^{75}$ Declaración Nostra Aetate sobre las relaciones de la Iglesia con las religiones no cristianas, 4.

${ }^{76}$ El grabado consta de un panel central, con Synagoga et Ecclesia, rodeado por veinticuatro pequeños paneles periféricos, cada uno con una cabeza representada frontalmente. Entre dichas cabezas, una presenta sus ojos cubiertos por una venda.
} 
a los dos atributos sobre los que Ecclesia apoya en sus manos, Menco, quien conoce la pasada tensión entre Ecclesia y Synagoga, comenta que "Iglesia ha bajado sus espadas cruciformes". ${ }^{77}$ En el grabado, dichas espadas son doblemente simbólicas, ya que sugieren belicosidad pero presentan además la apariencia de una cruz latina y otra greco-bizantina, involucrando así a las Iglesias latina y ortodoxa. Según el artista, el objetivo de su grabado es expresar que "Iglesia y Sinagoga son socias por partes iguales, en vez de una de ellas ser mejor que la otra". ${ }^{78}$

Ecclesia et Synagoga es un vitral creado por Helmut Heinemann para la iglesia parroquial de Santa Bárbara en Bonn-Ippendorf en 1995. Allí figuran las conocidas alegorías de la Fe. Ecclesia es identificable por la cruz latina; Synagoga por el rollo de la Torá. Las dos alegorías participan de un espacio común y tanto su actitud corporal como sus gestos sugieren un diálogo interreligioso. Sin embargo, el rollo de la Torá y los ojos de Synagoga están ambos cerrados. Ecclesia et Synagoga es a su vez el título de otro par de las alegorías de la Fe forjadas por la hermana Paula M. Turnbull. El par escultórico fue encomendado por Mary C. Boys para su libro ¿Posee Dios sólo una bendición? - Judaísmo como fuente de autoentendimiento cristiano (2000). ${ }^{79}$ Cada figura alegórica es una unidad independiente, mas ellas presentan características formales análogas: las dos poseen idéntica altura, ambas son de cobre y fueron representadas en un mismo estilo semi-abstracto. Cada alegoría es identificable por sus atributos específicos. Reconocible por la cruz latina y los símbolos eucarísticos, Ecclesia introduce a Synagoga, quien porta un manto de oraciones rituales hebreo (talit) y, a diferencia de su predecesora en Bonn, presenta aquí los rollos de la Torá abiertos. Ecclesia y Synagoga carecen las dos de rasgos faciales, mas también las vendas brillan aquí por su ausencia.

De neto corte alegórico, Synagoga y Ecclesia de Nuestro Tiempo es una escultura desarrollada por Joshua Koffman en 2015. El trabajo fue comisionado por la Saint Joseph's University de Filadelfia e importante para su creación fue la Exhortación Apostólica del Papa Francisco en 2013:

\footnotetext{
${ }_{77}$ Información provista por Menco en su website personal, 2010. THODOS, Diane. "Memory, Melancholy and Dreams: The Poetic Art of Bert Menco", Neoteric Art, 13 de octubre de 2015. ${ }^{78}$ Ibid. Descripción de la obra en Paddle 8, 2013.

${ }^{79}$ Has God Only One Blessing? Judaism as a Source of Christian Self-Understanding, Nueva York: Stimulus, 2000.
} 
El diálogo y la amistad con el pueblo judío son parte de la vida de los discípulos de Jesús. [...] Existe una rica complementariedad entre nosotros que nos permite leer los textos de la Biblia hebrea juntos y poder ayudarnos los unos a los otros a extraer las riquezas de la palabra de Dios. ${ }^{80}$

Consistentes con los contenidos de la declaración Nostra Aetate, estas premisas son evocadas en Synagoga y Ecclesia de Nuestro Tiempo. ${ }^{81}$ Realizada en estilo clásico, la obra de Koffman consta de dos alegorías de la $\mathrm{Fe}$, ambas sedentes y augustas en carácter. Cada una de ellas porta su respectiva corona. En su regazo, Synagoga presenta abiertos los rollos de la Torá. Por su parte, Ecclesia exhibe, también abierto, el libro del Evangelio. Evocando el método de aprendizaje dialéctico propio de las escuelas de estudios hebraicos, Koffman concibió sus alegorías en términos de javruta (חברותא), es decir, como auténticas compañeras de estudio. ${ }^{82}$ La proximidad de las figuras es aquí celebrada por una distendida actitud corporal que sugiere a su vez una relación cordial y armoniosa. Cada una de las alegorías se interesa por el texto portado por su compañera. La posición de los rostros de ambas, así como aquella de los soportes donde figuran sus Textos Sagrados, contribuyen todos a comunicar que Synagoga se interesa por el Evangelio en tanto que Ecclesia vuelve su mirada en dirección a la Torá. Realizada para el aniversario de la declaración Nostra Aetate, la escultura Synagoga y Ecclesia de Nuestro Tiempo celebra el reencuentro de quienes creen en la palabra de Dios y dialogan a partir de la amistad y el respeto mutuo. Durante su visita pastoral a los Estados Unidos, el Papa Francisco meditó ante esta imagen y la bendijo ante una multitud, conmovida por tan noble gesto. ${ }^{83}$

La dimensión trascendente de la alegoría de Koffman fue considerada en "Ayer y Hoy", una conferencia del Seminario Iglesia y Sinagoga en Diálogo,

\footnotetext{
${ }^{80}$ Evangelii Gaudium, §248-249. CunNingham, Philip A., et al. "A Statement from the International Council of Christians and Jews for the Golden Jubilee of the ... Declaration, Nostra Aetate", Conferencia Anual ICCJ, Roma, junio-julio 2015.

81 "SJU announces Details of Sculpture to mark 50 Years of New Catholic-Jewish Relation", SJU, 24 de abril de 2015.

${ }^{82}$ Término arameo empleado por el rabino Daniel Lehmann al describir la nueva relación entre judíos y católicos, 2004. Lo esencial en toda javruta es el diálogo. No se trata de estar de acuerdo en todo, sino de considerar un punto de vista diferente al propio - uno que pueda llegar a enriquecer la perspectiva propia a partir del diálogo que es mantenido con el interlocutor.

83 "Pontiff Makes Historic Visit to Philadelphia's Jesuit University", SJU, comunicado de prensa, 27 de septiembre de 2015.
} 
que tuvo lugar en el Departamento de Teología de la Pontifícia Universidade Católica do Rio de Janeiro al conmemorase el $50^{\circ}$ aniversario de Nostra Aetate en $2015 .^{84}$ En tal ocasión, quien escribe se refirió a la importancia de Synagoga y Ecclesia de Nuestro Tiempo como estímulo para el diálogo interreligioso y como ejemplo para las generaciones presentes y venideras. $\mathrm{La}$ obra le recuerda al espectador que católicos y judíos no son ya ajenos, sino que comparten logros pasados y desafíos tanto presentes como futuros. ${ }^{85} \mathrm{En}$ cuanto a la historia del arte, la imagen de Koffman revierte el viejo modelo de la antinomia y el desencuentro, propulsando una nueva relación: constructiva y basada en la cooperación y el aprendizaje conjunto. ${ }^{86}$

En la mencionada conferencia, la obra de Koffman fue considerada junto con SynClesia (2014), un collage digital realizado y exhibido con propósitos dialécticos, por quien escribe.$^{87}$ Caracterizada por la ubicuidad de la venda y su intrigante simbolismo, SynClesia rechaza el suponer que, en materia de creencia y diálogo interreligioso, las vendas son hoy asunto del pasado. Si bien el diálogo interreligioso ha demostrado ser enriquecedor ${ }^{88}$ cierto es también que en varios casos las vendas lejos están aún de haber desaparecido por completo, particularmente en lo que concierne a las alegorías de la Fe ${ }^{89}$ A diferencia de la imagen de

${ }^{84}$ Akerman, Luís Mariano. "Ontem e Hoje: As Alegorias da Fé no Imaginário Visual de Ocidente”. In: Río de Janeiro, Consulado Geral da Bélgica, Programa Estimulo Vesalius: Anatomia da Arte, 2014-2015: Conferências, 11.

${ }^{85}$ Evangelii Gaudium, §247. SKORKA, Abraham. "50 Years of Nostra Aetate", discurso, SJU, 25 de septiembre de 2015.

86 "The Medieval Motif of Ecclesia et Synagoga and Its Transformation in a post-Nostra Aetate Church", SJU, julio de 2015.

${ }^{87}$ Conferencia "Um Tempo para Tudo", Río de Janeiro, Centro de Estudos Bíblicos da ARI, 21 de octubre de 2014.

${ }^{88}$ Cunningham, “A Statement”, 2015.

${ }^{89}$ Considérense: la venda que cubre los ojos de Synagoga en el vitral realizado por Oswin Amann en 1950 para la iglesia del Sagrado Nombre de Jesús en Viena y aquella de la Alegoría de la Fe católica recientemente adoptada para las procesiones de Semana Santa en Sevilla. Ver también las vendas en: el dibujo a tinta china de Daniel Mitsui, El árbol de la vida y la muerte II, 2006-7; la imagen de Ana Cruz, Joven con venda, 2009; la escultura de Kris Kuksi, Una abducción heroica, 2010; el dibujo alemán para la "Semana de la Hermandad", con Synagoga colocando una venda sobre los ojos de Ecclesia, Ansbach, 2012; el fotomontaje de Barbara Kruger, Creencia y duda es salud, 2012; la interpretación de "Synagoga" por Helena Efferová en Anima/Animus, catedral de Winchester, 2013; el tríptico de Scott Freeman, El muro remanente, 2013; y la ilustración de Pepe Fainberg para "The People and the Book", The Jerusalem Report, 23 de agosto de 2015. 
Koffman, SynClesia, no es clara, ni tierna, ni idílica, sino misteriosa, dura e inquietante. Como figura, SynClesia involucra una cabeza de piedra fotografiada frontalmente. Se trata de una imagen compuesta, es decir, un todo obtenido a partir de la yuxtaposición de dos medias-imágenes. La mitad derecha de SynClesia pertenece a "España defensora de la Fe", en tanto que la izquierda proviene de Synagoga, alegoría escultórica medieval de la catedral de Metz. Ambas llevan una venda sobre los ojos. En SynClesia, las vendas y los rasgos faciales de las protagonistas están articulados de modo tal que una continuidad visual se crea entre ellos. Así, los rasgos de las figuras son coincidentes, en tanto que la venda que porta la una se continúa también en la otra. En 2014, SynClesia fue presentada junto con una paráfrasis del libro del Eclesiastés:

Un tiempo hay para todo bajo del cielo.

Un tiempo para indicar la ceguera del vecino

$\mathrm{Y}$ un tiempo para reconocer la ceguera propia.

Un tiempo para insistir sobre las diferencias

$\mathrm{Y}$ un tiempo para reconocer las semejanzas.

Un tiempo para distanciarse

Y un tiempo para reconciliarse..$^{90}$

Al ser SynClesia reconsiderada en 2015, quien escribe expresó que, en ella y otras alegorías de la $\mathrm{Fe}$, la venda es un atributo equívoco, pudiendo ser su presencia tanto negativa como positiva. Negativa en tanto que la venda constituya un muro entre los distintos creyentes y genere autocomplacencia y desconocimiento del prójimo; positiva si la venda es símbolo de Fe auténtica - aquella que nada tiene que ver con los ojos, pero sí todo con el corazón. ${ }^{91}$ Propiciatoria del autocuestionamiento y estimulando el intercambio de ideas, SynClesia fue a su vez caracterizada por su autor en términos de yuxtaposición de diferencias teológicas y puente de afinidades espirituales. ${ }^{92}$

\footnotetext{
${ }^{90}$ AKERMAN, “Um Tempo para Tudo”, 2014.

${ }^{91}$ Considerados en este contexto fueron los textos de Éxodo 24, 7 y Hebreos 11:1.

${ }^{92}$ Akerman, "Ontem e Hoje”, 2015.
} 


\section{Conclusión}

Desde sus orígenes, la alegoría presenta aspectos misteriosos y contradictorios. Intenta ella servir de ejemplo, pero simultáneamente da lugar a varias lecturas posibles e invita así al equívoco y el malentendido. Con sus ojos cubiertos por una venda, la alegoría de la Justicia, por ejemplo, ha sido blanco de controversias, incredulidad y ridiculización. ${ }^{93}$ Elaboradas a veces con fines ilustrativos, las alegorías fueron no obstante empleadas también con intenciones propagandísticas y proselitistas, desde la antigua Roma y hasta después de la Revolución Francesa y los totalitarismos del siglo XX.

Como entidad retórica que es, la alegoría acaso lo sugiera todo, pero de hecho no define nada. Invocando abstracciones, las alegorías son personificaciones que ostentan símbolos diversos. Inventos y fabricaciones articuladas a consciencia, las alegorías son representaciones indirectas y artificiales, cuando no generalizaciones con pretensiones de atemporalidad, llegando incluso a dar lugar a interpretaciones erróneas y conclusiones simplistas. Ergo, ellas pueden ser a veces problemáticas.

El par de Ecclesia et Synagoga fue desarrollado durante el medioevo $\mathrm{y}$ es frecuente en el arte católico desde el siglo XII en adelante. Mas no existe en el arte hebreo, donde sólo Synagoga es evocada ocasional e indirectamente a través de las figuras de la amada (Mahzor Levi, 1350) y la Reina del Shabat (Judá, 1900-1). En el arte cristiano, por otra parte, Ecclesia es representada convencionalmente y sin mayores modificaciones. Distinto es el caso de Synagoga. Ella sufre transformaciones drásticas y un enorme deterioro. Incorporada inicialmente en marfiles carolingios y otonianos como contrapunto de Ecclesia en escenas de la Crucifixión, Synagoga fue posteriormente reformulada en términos cada vez más negativos: de curiosa o apática ante Jesús en la cruz, Synagoga pasó a portar la venda y ser rival de Ecclesia, contrincante derrotada, responsable de deicidio, agente del demonio y hasta objeto de la venganza del "Crucifijo viviente". ${ }^{44}$ Salvo rarísimas excepciones donde la Divinidad interviene y remueve la venda que hasta

\footnotetext{
${ }^{93}$ RESNIK; CURTIS, Representing Justice, capítulos. 4-5. La venda funcionando como símbolo ambiguo, pp. 14, 62, 95.

94 Timmerman, Achim. "The Avenging Crucifix: On the Iconography of the Living Cross". Gesta 40:2 (2001), pp. 141-160.
} 
entonces cubría los ojos de Synagoga,${ }^{95}$ tensa y conflictiva es la relación entre Ecclesia y Synagoga, durante no menos de doce siglos.

Aún hoy el par Ecclesia "triunfante" y Synagoga "derrotada" sigue presente en la realidad occidental. Figura en no pocos templos católicos y museos europeos. Eventualmente el par es "leído" en términos que se desentienden del legado del Concilio Vaticano II y desafian la actual posición de la Iglesia católica en materia interreligiosa. ${ }^{96}$ Con todo, el efecto de Nostra Aetate se hace sentir en las artes visuales, donde la relación entre Ecclesia y Synagoga tiende gradualmente a transformarse. Notables son en este sentido las contribuciones de Hämmerle, Menco y Turnbull, mientras que aquella de Koffman expresa magníficamente las premisas de Nostra Aetate y la prédica del Papa Francisco.

Además de las conocidas alegorías de Synagoga, numerosas alegorías de la $\mathrm{Fe}$ católica fueron ejecutadas en el arte europeo a partir del siglo XIV. Ellas portan los atributos de Ecclesia, más suelen también llevar sus ojos cubiertos por una venda. Este último aspecto concierne a más de una quincena de alegorías de la Fe católica realizadas en España y allí veneradas hasta el día de hoy.

Contrariamente a toda expectativa, la venda sigue aún vigente en el arte de nuestro tiempo. A diferencia de aquellos símbolos que caracterizan unívocamente las alegorías de la Fe, la venda es un atributo ambiguo y susceptible de comunicar ideas opuestas. Ello se verifica en las alegorías de

\footnotetext{
${ }^{95}$ La venda de Synagoga es removida sólo excepcionalmente en el arte medieval. En un vitral de basílica de Saint Denis (París, siglo XII), Cristo bendice a Ecclesia y remueve la venda que, según la teología eclesiástica medieval, cubría hasta entonces los ojos de la Fe mosaica (FAÜ, fig. 13). Es decir, sólo a través de la conversión al Cristianismo los judíos se vuelven aceptables y llegan a percibir el mensaje de la Iglesia. Análoga es la escena en un relieve de las fuentes bautismales de Selincourt, Picardía (Musée d'Amiens; FAÜ, fig. 14). En dos miniaturas de la Biblia Lambeth (Canterbury, 1150-1170), la Mano de Dios descubre el velo de los ojos de Synagoga (Londres, Lamberth Palace, Ms. 3, fols. 198, 307). Sobre la "ceguera" de los judíos y su "curación", ver PEREDA, F. "La conversión por la imagen y la imagen de la conversión". In: CANALDA, S., et al. Cartografias visuales y arquitectónicas de la Modernidad. Universitat Barcelona, 2011, pp. 227-241.

${ }^{96}$ Información sobre La Fuente de la Gracia que provee el Museo Nacional del Prado, Madrid, catálogo online, 2010-2015: "Las Sagradas Formas [...] convierten el agua en símbolo de Gracia, que ilumina a la Iglesia Triunfante y ciega a la Sinagoga, es decir, a los judíos que no reconocen a Cristo". Todo en tiempo presente. El marco de la obra lleva una leyenda con la inscripción "La Fuente de la Gracia", mas ello es reformulado a través de un apéndice adosado al título de la obra y emitido desde el anonimato: "La Fuente de la Gracia y Triunfo de la Iglesia sobre la Sinagoga" (accedido: 19/11/2010 y 17/12/2015).
} 
la Fe mosaica y Fe católica que presentan sus ojos cubiertos por una venda. Más allá de sus especificidades, todas las alegorías de la Fe que involucran la venda pueden ser interpretadas a partir de consideraciones teológicas y están expuestas a ser entendidas como expresiones de Fe ciega o bien de Fidelidad incondicional. Ello se da también en SynClesia, configuración de doble-filo que enlaza instituciones otrora aisladas, mas actualmente en diálogo. Decisiva en SynClesia es la venda, cuya presencia invita a cuestionarse qué es exactamente la Fe. Manifestándose como una paradoja visual, la venda promueve aquí la introspección, el diálogo interreligioso y hasta alude al misterio de la $\mathrm{Fe}$. ¿O acaso no es el texto bíblico al creyente lo que la venda es a la Fe? La respuesta a ello es paradójica y lo es por partida doble: "sólo se ve bien con el corazón" y se avanza no por la vista, sino por la Fe. ${ }^{97}$

\section{Referencias bibliográficas}

AKERMAN, Luís Mariano. "Las alegorías de la Fe: imágenes y recursos digitales", Asterisk, 21 de diciembre de 2015. Disponible en: <http://akermariano.blogspot.com/2015/12/fe.html>. Accedido: 27/12/2015.

BLANC, J. "L'allégorie: l'invisible et sa représentation". In: FRONTISI, Claude. Histoire visuelle de l'art, París: Larousse, 2001, pp. 212-13.

CIRLOT, José Eduardo. A Dictionary of Symbols (1958). Londres: Routledge, 1971.

COFRADÍA DE LASANTAFE. Revista Fe y Hermandad, Lucena, 2013: “Año de la Fe". Disponible en: <http://cofradiasantafe.blogspot.com/2013/03/ revista-fe-y-hermandad-2013.html $>$. Accedido: 18/12/2015.

CUNNINGHAM, Philip A., et al. "A Statement from the International Council of Christians and Jews for the ... Jubilee of ... Nostra Aetate", Roma, junio-julio 2015. Disponible en: <http://www.ccjr.us/dialogikaresources/documents-and-statements/interreligious/iccj/1339-iccj2015june30>. Accedido: 15/12/2015.

FARFÁN, L. "El Cerro de los Ángeles", Una ventana desde Madrid, 11 de

${ }^{97}$ SAINT-EXUPÉRY, Le Petit Prince, cap. XXI; 2 Corintios 5, 7. 
diciembre de 2013. Disponible en: < http://www.unaventanadesdemadrid. com/comunidad-de-madrid/cerro-de-los-angeles.html>. 15/12/2015.

FAÜ, Jean-François. L'image des Juifs dans l'art chrétien médiéval. París: Maisonneuve \& Larose, 2005.

$\mathrm{KOCH}$, K. "Theological Perspectives in Jewish-Catholic Dialogue". Conferencia ICCJ, Nueva Jersey, 2011.

"La Fuente de la Gracia y Triunfo de la Iglesia sobre la Sinagoga". Museo Nacional del Prado, Madrid, catálogo, 2010-2015. Disponible en: $<$ https:// www.museodelprado.es/coleccion/obra-de-arte/la-fuente-de-la-graciay-triunfo-de-la-iglesia/f578c5af-b1d6-4ef8-aaa3-ae05a6dd2393>. Accedido: 19/11/2010 y 17/12/2015.

MICHAEL, Robert. A History of Catholic Antisemitism. Palgrave-Macmillan, 2008.

RESNIK, J.; CURTIS, D. "From Fool's Blindfold to the Veil of Ignorance". Yale Law Report 58:1 (2011), pp. 14-16.

REUTER, Jasmín. “Alegoría de la Sinagoga”. Revista de la Universidad de México 20:1 (1965), pp. 18-20.

RIPA, Cesare. Iconologia overo descrittione dell'imagini universali, 2a ed., Roma: Lepido Facij, 1603.

ROWE, Nina. "Idealization and Subjection at the South Façade of Strasbourg Cathedral". In: MERBACK, M., ed. Beyond the Yellow Badge: AntiJudaism and Antisemitism in Medieval and Early Modern Culture. Leiden: Brill, 2007, pp. 179-202.

SAINT-EUPÉRY, Antoine de. Le Petit Prince (1943). París: Gallimard, 1951.

WELCH, B. "Fides: Loyalty and Trust", The Sign Language of Roman Coins, 18 de octubre de 2008. Disponible en: $<$ https://www. forumancientcoins.com/moonmoth/reverse_fides.html $>$. Accedido: $17 / 12 / 2015$. 
Arquitecto especializado en Comunicación Visual por la Universidad de Belgrano, Buenos Aires Master of Arts en Historia del Arte por la Universidad Hebrea de Jerusalén Docente de Posgrado en Programas Educativos Internacionales del MAEB Buenos Aires E-mail: akermariano@yahoo.fr

Recebido em: 27/12/15 Aprovado em: 01/06/16 